\title{
Trauma electives in South Africa provide valuable training for international surgeons
}

\author{
H Uchino, ${ }^{1}$ MD, MMedSci; V Y Kong, ${ }^{2,3}$ MB ChB, ChM, MSc, PhD, MRCS (Ed); F Plani, ${ }^{2,4}$ MD, FCS (SA), FRACS; \\ W Bekker, ${ }^{3}$ FCS (SA); V Manchev, ${ }^{3}$ FCS (SA); J L Bruce, ${ }^{3}$ FCS (SA); G L Laing, ${ }^{3}$ PhD, FCS (SA); \\ D L Clarke, ${ }^{2,3} \mathrm{MB}$ BCh, MMedSci, MBA, MPhil, PhD, FCS (SA) \\ ${ }^{1}$ Department of Surgery, Kurashiki Central Hospital, Okayama, Japan \\ ${ }^{2}$ Department of Surgery, Faculty of Health Sciences, University of the Witwatersrand, Johannesburg, South Africa \\ ${ }^{3}$ Department of Surgery, College of Health Sciences, University of KwaZulu-Natal, Durban, South Africa \\ ${ }^{4}$ Trauma Directorate, Chris Hani Baragwanath Hospital, Johannesburg, South Africa
}

Corresponding author: V Kong (victorywkong@yahoo.com)

\begin{abstract}
Background. Trauma electives in South Africa (SA) are common and many foreign-based surgeons have undertaken such electives over the past 3 decades. Despite this, little academic attention has been paid to these electives, which remain largely informal and unstructured. This project aims to redress this deficit.

Objectives. To investigate and document the extent of trauma clinical electives and to assess their impact on the careers of foreign surgeons who have undertaken such electives.

Methods. A mixed methods-style questionnaire was compiled, which sought to document the demographics of surgeons undertaking an SA trauma clinical elective, the trauma clinical experience they had prior to the elective, as well as the volume of experience they acquired during the elective.

Results. Sixty questionnaires were sent out and 21 were completed. There were 16 male and 5 female respondents. Only 17 had undertaken a formal trauma rotation before their elective in SA. The mean number of major resuscitations managed prior to rotating through surgery departments in SA was 15, and the mean number managed during a 12-month rotation in SA was 204. It would take each respondent 14 years in their country of origin to acquire an equivalent level of exposure to major resuscitation. During the year before their elective, each surgeon had been exposed to a mean number of the following: 0.5 gunshot wounds (GSWs), 2 stab wounds (SWs), 0.1 blast injuries and 19 road traffic accidents (RTAs). The equivalent mean number for their year in SA was 106 GSWs, 153 SWs, 4 blast injuries and 123 RTAs. The time necessary to achieve a similar level of exposure to their SA experience if they had remained in their country of origin was 213 years for GSWs, 73 years for SWs, 41 years for blast injuries and 7 years for RTAs. Compared with their SA elective, it would take each respondent 3 years to insert as many central venous lines, 9 years to perform the same number of tube thoracostomies, 9 years to manage as many surgical airways, 18 years to explore as many SWs of the neck and 93 years to explore as many GSWs of the neck. Furthermore, it would take 33 years to see and perform as many laparotomies for SWs to the abdomen, 374 years to perform an equivalent number of GSWs to the abdomen and 34 years of experience to perform as many damage-control laparotomies in their countries of origin. In terms of vascular trauma, it would take 23 years to see as many vascular injuries secondary to SWs and 77 years to see an equivalent number of vascular injuries secondary to GSWs.

Conclusions. A trauma clinical elective in SA provides an unparalleled exposure to almost all forms of trauma in conjunction with a welldeveloped academic support programme. Formalising these trauma electives might allow for the development of exchange programmes for SA trainees who wish to acquire international exposure to advanced general surgical training.
\end{abstract}

S Afr Med J 2019;109(3):182-185. DOI:10.7196/SAMJ.2019.v109i3.13551

As surgery has advanced over the past several decades, the need for subspecialist training programmes has grown. Increasingly, general surgical residency programmes do not seem to be able to provide trainees with a complete set of skills necessary to manage the modern surgical patient holistically. This has led to the development of subspecialist programmes in South Africa (SA) and globally. ${ }^{[1,2]}$ These are usually referred to as fellowships. In SA and the USA, surgical fellowships may allow for trainees to obtain a formal subspecialist qualification at the end of the rotation. Many trainees do not sit the formal subspecialist examination, but undertake the fellowship for the practical and clinical exposure. These are sometimes termed 'clinical electives' to distinguish them from formal fellowships. International clinical electives are increasingly popular and many surgeons try to spend 1 or 2 years in a foreign environment during their careers. There are many reasons for this, including social intangibles, such as travel and exposure to foreign cultures and environments, as well as those pertaining to clinical practice. SA trauma experience and trauma training remain highly thought of worldwide. The huge burden of trauma in SA, combined with access to modern surgical resources and underpinned by a strong academic foundation, has made a clinical elective in SA trauma centres an important part of many surgeons' training. ${ }^{[3-6]}$ Over the past 3 decades, numerous foreign-based surgeons at a variety of levels of training have undertaken a trauma clinical elective in SA. Despite the popularity of these clinical electives, they remain unformalised and relatively unstructured and there has been almost no academic review of their impact and role. This study aims to investigate and document the extent of these trauma clinical electives and to assess 
their impact on the careers of the various foreign surgeons who undertook them.

\section{Methods}

A mixed methods-style questionnaire was compiled, which sought to document the demographics of surgeons undertaking an SA trauma clinical elective, their clinical experience in trauma before the elective, as well as the volume of experience they acquired during the elective. The survey is set out in Appendix $1 .^{*}$

\section{Ethical approval}

Ethical approval for this study was formally endorsed by the Biomedical Research Ethics Committee (BREC) of the University of KwaZulu-Natal, Durban, SA (ref. no. BE083/14).

\section{Results}

Sixty questionnaires were sent out, of which 21 were completed. There were 16 male and 5 female respondents. The country of origin of each trainee is shown in Table 1 . There were 17 general surgeons, 3 emergency physicians and 1 paediatric surgeon among the respondents. Their current subspecialty interests were trauma and critical care $(n=4)$, vascular surgery $(n=5)$, cardiac surgery $(n=1)$, colorectal surgery $(n=1)$, emergency medicine $(n=2)$, hepatobiliary surgery $(n=1)$, general surgery $(n=1)$, intensive care medicine $(n=2)$ and urology $(n=1)$. Of the respondents, only 17 had undertaken a formal trauma rotation prior to their elective in SA. In only 3 cases was this rotation at a level 1 trauma centre, as defined by the American College of Surgeons (ACS). Of the respondents, 17 felt that their career had benefited as a result of their clinical elective. The mean number of major resuscitations managed before their SA rotation was 15 , and the mean number managed during a 1-year rotation in SA was 204. It would take each respondent 14 years in their country of origin to acquire an equivalent level of exposure to major resuscitation. During the year prior to their elective, each surgeon had been exposed to a mean of 0.5 gunshot wounds (GSWs), 2 stab

\begin{tabular}{ll} 
Table 1. Country of origin of trainees \\
\hline Country & Questionnaire respondents, $\boldsymbol{n}$ \\
\hline Japan & 5 \\
Sweden & 5 \\
UK & 3 \\
Belgium & 1 \\
New Zealand & 1 \\
The Netherlands & 1 \\
India & 1 \\
Congo & 1 \\
Gabon & 1 \\
Ghana & 1 \\
Kenya & 1
\end{tabular}

wounds (SWs), 0.1 blast injuries and 19 road traffic accidents (RTAs). The equivalent means for their year in SA were 106 GSWs, 153 SWs, 4 blast injuries and 123 RTAs. The time necessary to achieve a similar level of exposure to their SA experience if they had remained in their country of origin was 213 years for GSWs, 73 years for SWs, 41 years for blast injuries and 7 years for RTAs. Table 2 summarises the pre- and post-rotation exposure to different types and mechanisms of trauma of the 21 respondents. Compared with their SA elective, it would take each respondent 3 years to insert as many central venous lines, 9 years to perform the same number of tube thoracostomies, 9 years to manage as many surgical airways, 18 years to explore as many SWs of the neck and 93 years to explore as many GSWs of the neck in their countries of origin. The same applies to laparotomies for trauma. It would take 33 years to see and perform as many laparotomies for SWs to the abdomen and 374 years to perform an equivalent number of laparotomies for GSWs to the abdomen. It would also require 34 years of experience to perform as many damage-control laparotomies. With regard to vascular trauma, it would take 23 years to observe as many vascular injuries secondary to SWs and 77 years for an equivalent number of vascular injuries secondary to GSWs. Table 3 summarises the exposure each trainee had to procedures in trauma before and after their elective in SA. The final column of each table lists the estimated length of time it would have taken to achieve this level of clinical exposure had these surgeons not undertaken a clinical elective in SA.

\section{Discussion}

Trauma training and trauma preparedness are increasingly areas of concern worldwide. Formal military conflicts over the past 2 decades have ensured that most military surgeons have been exposed to a significant volume of trauma. This experience is reflected in the large body of literature that has emerged as a result of these conflicts. ${ }^{[5,6]}$ Currently, it would appear that even though these formal conflicts are over, some form of asymmetric warfare is likely to continue for the immediate future. This era of asymmetric warfare means that trauma might occur in unexcepted areas away from the formal frontlines of conflict, as evidenced by the spread of urban terrorism, which over the past 5 years has blighted many major European cities. ${ }^{[5,6]}$ Furthermore, ongoing social change such as mass migration and urban poverty means that interpersonal trauma is once again on the rise in major European cities. ${ }^{[7-9]}$ Therefore, trauma preparedness is a great concern. It is up to surgeons and emergency physicians worldwide to ensure that they have sufficient experience and institutional knowledge to treat such trauma cases.

There has been a response to this challenge: countries such as Australia have adopted guidelines, e.g. the Tactical Combat Casualty Care (TCCC) Guidelines, and the Joint Trauma System (JTS) of the US Army Institute of Surgical Research. ${ }^{[10-13]}$ Other countries have followed suit. However, despite the widespread introduction of military-style training systems, which seek to impart the experience gained during the recent major conflicts to civilian practitioners,

Table 2. Pre- and post-rotation exposure to different types and mechanisms of trauma

\begin{tabular}{llll}
\hline Trauma & $\begin{array}{l}\text { Prior exposure } \\
\text { (average per year, } \boldsymbol{n} \text { ) }\end{array}$ & $\begin{array}{l}\text { Exposure during South African } \\
\text { elective (average per year, } \boldsymbol{n} \text { ) }\end{array}$ & $\begin{array}{l}\text { Time estimated to acquire the same level of } \\
\text { experience in country of origin (years) }\end{array}$ \\
\hline Major trauma resuscitation & 15.0 & 204 & 14 \\
Gunshot wounds & 0.5 & 106 & 213 \\
Stab wounds & 2.0 & 153 & 73 \\
Blast injuries & 0.1 & 4 & 41 \\
Road traffic accidents & 19.0 & 123 & 7
\end{tabular}


Table 3. Pre- and post-rotation exposure to medical procedures

\begin{tabular}{llll}
\hline Procedure & $\begin{array}{l}\text { Prior to SA rotation } \\
\text { (average per year, } \boldsymbol{n} \text { ) }\end{array}$ & $\begin{array}{l}\text { During SA rotation } \\
\text { (average per year, } \boldsymbol{n} \text { ) }\end{array}$ & $\begin{array}{l}\text { Time estimated to acquire the same level } \\
\text { of experience in country of origin (years) }\end{array}$ \\
\hline CVP line & 9.8 & 29.2 & 3 \\
Chest tube & 5.9 & 50.1 & 9 \\
Intubation & 14.5 & 17.9 & 1 \\
Surgical airway & 0.4 & 3.4 & 9 \\
Neck exploration - SW & 0.3 & 5.4 & 18 \\
Neck exploration - GSW & 0.03 & 2.8 & 93 \\
Neck exploration - blunt & 0.08 & 0.3 & 4 \\
Thoracotomy - SW & 0.2 & 12.6 & 63 \\
Thoracotomy - GSW & 0.02 & 3.7 & 185 \\
Thoracotomy - blunt & 0.5 & 2.9 & 6 \\
Laparotomy - SW & 1.0 & 33.3 & 33 \\
Laparotomy - GSW & 0.07 & 26.2 & 374 \\
Laparotomy - blunt & 1.3 & 12.5 & 10 \\
Laparotomy - damage control & 0.7 & 23.9 & 34 \\
Peripheral vascular trauma - SW & 0.3 & 7.0 & 23 \\
Peripheral vascular trauma - GSW & 0.07 & 5.4 & 77 \\
Peripheral vascular trauma - blunt & 0.3 & 2.0 & 7 \\
SA = South Africa; CVP = central venous pressure; SW $=$ stab wound; GSW = gunshot wound. & &
\end{tabular}

there is a low rate of penetrating and ballistic trauma in countries in western Europe and Australasia. Consequently, it is difficult for emergency staff to obtain real-life clinical experience in the management of these injuries.

After 25 years of democracy, SA remains a country of contrasts. ${ }^{[3,4]}$ It has a sophisticated infrastructure, yet it is plagued by huge socioeconomic disparities and a stubbornly persistent high burden of trauma. The latter has allowed SA trauma surgeons to obtain a huge volume of experience in the management of trauma and to acquire an international reputation for excellence. This experience has been documented in a sustained output of publications over the past 60 years. ${ }^{[3,4,14]}$ In addition, the development of trauma as a subspecialty and the ongoing drive to accredit trauma centres have ensured that SA trauma care continues to be held in high esteem globally. This unique combination of clinical load, infrastructure and academic output makes a clinical elective in trauma attractive to foreign surgeons.

If the trauma electives are to be used as leverage to develop and enhance SA surgical training in general, these may need to be formalised. Currently, the situation is somewhat anomalous, as SA institutions provide training to doctors of other countries and receive no formal remuneration. Apart from the intangibles, such as reputation and goodwill, these electives provide no sustainable systematic benefit to SA institutions. This is short sighted, as there are many potential benefits, including access to advanced laparoscopic and transplant training for SA trainees, who will be able to rotate through international centres of excellence. ${ }^{[15]}$ The formal development of research links may also allow SA institutions to increase their access to major international collaborative funding and laboratory-based research.

\section{Conclusion}

A trauma clinical elective in SA provides an unparalleled exposure to almost all forms of trauma in conjunction with a well-developed academic support programme. The trainees who completed such an elective all felt that the clinical exposure was of inestimable value. Formalising these trauma electives may provide SA training programmes with international exposure and allow for the development of exchange programmes for SA trainees who seek advanced general surgical training abroad.

${ }^{*}$ Supplementary information. Appendix 1 is available from the corresponding author on request.

Declaration. This study was part of the Master of Medical Science thesis of HU, undertaken at the University of KwaZulu-Natal, Durban, South Africa. Acknowledgements. The completion of this study would not have been possible without the support of Mr George Oosthuizen, Chief of Surgery at Ngwelezana Hospital, South Africa. Thanks also to Ms Tracey Hudson, recruitment officer of Africa Health Placements.

Author contributions. HU: development of tool, administration and collation of responses; VY: development of tool; FP: administration of questionnaire; WB, VM: process control and collation of responses; JLB, GLL: analysis of responses; DLC: overall supervision of project.

Funding. None.

Conflicts of interest. None.

1. RCSEd International Surgical Fellowship Programme. https://www.rcsed.ac.uk/professional-supportdevelopment-resources/grants-jobs-and-placements/uk-training-opportunities-for-internationaltrainees/rcsed-international-surgical-fellowship-programme (accessed 23 January 2019).

2. Are surgical/medical fellowships in USA worth the time and effort? https://www.quora.com/Are Surgical-medical-fellowships-in-USA-worth-the-time-and-effort (accessed 23 January 2019).

3. Hardcastle TC, Oosthuizen G, Clarke DL, Lutge E. Trauma, a preventable burden of disease in South Africa: Review of the evidence, with a focus on KwaZulu-Natal. S Afr Health Rev 2016;1:179-189.

4. Hardcastle TC, Samuels C, Muckart DJ. An assessment of the hospital disease burden and the facilities for the in-hospital care of trauma in KwaZulu-Natal, South Africa. World J Surg 2013;37(7):1550-1561. https://doi.org/10.1007/s00268-012-1889-1

5. Uchino H, Kong VY, Clarke DL, et al. Can we train military surgeons in a civilian trauma center? World J Surg 2018;42(1):26-31. https://doi.org/10.1007/s00268-017-4149-6

6. Uchino H, Kong VY, Clarke DL, et al. Preparing Japanese surgeons for potential mass casualty situations

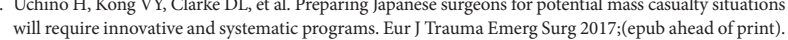
will require innovative and systematic progra

https://doi.org/10.1007/s00068-017-0871-x
7. Transcript of shocking evidence from London trauma surgeon Martin Griffiths on young victims of Transcript of shocking evidence from London trauma surgeon Martin Griffiths on young victims of
knife and gun crime. https://rosslydall.wordpress.com/2018/04/05/transcript-of-shocking-evidencefrom-london-trauma-surgeon-martin-griffiths-on-young-victims-of-knife-and-gun-crime/ (accessed 5 April 2018).

8. Roundtree C. Surgeon says he is regularly treating children in school uniform for gun and knife wounds in London hospital which is 'like Afghan war zone'. Mail Online, 6 May 2018. http://www. dailymail.co.uk/news/article-5581331/London-surgeon-says-regularly-treating-children-schooluniform-gun-knife-wounds.html (accessed 6 May 2018)

9. Torjesen I, Gulland A. Manchester doctors describe aftermath of bomb blast as NHS continues to treat casualties. BMJ 2017;357:j2628. https://doi.org/10.1136/bmj.j2628

10. Gowing JR, Walker KN, Elmer SL, Cummings EA. Disaster preparedness among health professionals and support staff: What is effective? An integrative literature review. Prehosp Disaster Med 2017;32(3):321-328. https://doi.org/10.1017/S1049023X1700019X 
11. Rosenfeld JV, Mitra B, Reade MC, et al. Preparedness for treating victims of terrorist attacks in Australia: Learning from recent military experience. Emerg Med Australas 2018;(epub ahead of print). https://doi.org/10.1111/1742-6723.13091

12. Davey TM, Pollard CW, Aitken LM, et al. Tackling the burden of injury in Australasia: Developing a binational trauma registry. Med J Aust 2006;85(9):512-514. https://doi.org/10.5694/j.1326-5377.2006. tb00668.x

13. Haverkamp FJC, Veen H, Hoencamp R, et al. Prepared for mission? A survey of medical personnel training needs within the International Committee of the Red Cross. World J Surg 2018; (epub ahead of print). https://doi.org/10.1007/s00268-018-4651-5
14. Clarke DL, Thomson SR, Madiba TE, Muckart DJ. Selective conservatism in trauma management: A South African contribution. World J Surg 2005;29(8):962-965. https://doi.org/10.1007/s00268-005-

15. Look who's going to California! Durban academic scores US gig. Times Live, 11 June 2018. https:// www.timeslive.co.za/news/south-africa/2018-06-11-look-whos-going-to-california-durbanacademic-scores-us-gig/ (accessed 11 June 2018)

Accepted 27 August 2018. 